\title{
Análise do jogo MixQuímico no ensino de química segundo o contexto da teoria da aprendizagem significativa
}

Felipe Alves Silveira felipesilveiraquimica@gmail.com 0000-0003-3851-232X Instituto Federal de Educação, Ciência e Tecnologia do Ceará, Maracanaú, Ceará, Brasil.

Ana Karine Portela Vasconcelos karine portela@hotmail.com 0000-0003-1087-5006

Instituto Federal de Educação, Ciência e Tecnologia do Ceará, Maracanaú, Ceará, Brasil.

Caroline de Goes Sampaio carol-quimica@hotmail.com 0000-0002-3642-234X

Instituto Federal de Educação,

Ciência e Tecnologia do Ceará,

Maracanaú, Ceará, Brasil.

\section{RESUMO}

A investigação tem como objetivo analisar o uso de um jogo pedagógico de tabuleiro no processo de ensino e aprendizagem de Química sob o contexto da Teoria da Aprendizagem Significativa. O jogo é composto de um tabuleiro construído com materiais de baixo custo com quatro divisões que abordam diferentes conteúdos de Química. Os sujeitos da pesquisa foram estudantes da $1^{\circ}$ série do Ensino Médio de uma escola estadual profissionalizante em Fortaleza. Utilizou-se como campo metodológico uma abordagem qualitativa pautada no estudo de caso. Conforme os resultados os estudantes apresentaram evolução dos seus conceitos adquiridos nos quais foram sendo aprimorados perante a aquisição de novos significados através do uso do jogo MixQuímico. Esse corroborou uma chance a mais de assimilar o conteúdo que foi estudado e contribuiu para identificar indícios de uma Aprendizagem Significativa. Com base ainda nos resultados obtidos concluiu-se na eficácia do jogo enquanto material didático de apoio.

PALAVRAS-CHAVE: Ensino de química. Jogo de tabuleiro. Aprendizagem significativa. 


\section{INTRODUÇÃO}

A Química procura explicar diversos fenômenos da natureza e esse conhecimento pode ser utilizado em benefício da própria sociedade. Mesmo que essa disciplina esteja diretamente relacionada ao meio em que vive, a sociedade, os estudantes acabam considerando-a difícil, ou seja, complicada de aprender. Diante disso, deve-se buscar recursos metodológicos diferenciados para ajudar no processo de ensino e aprendizagem que condicione a uma aula que corrobore para a aprendizagem que leve em consideração aquilo que o estudante já possui de conhecimento.

A disciplina de Química está relacionada a diversos aspectos do mundo e seu estudo foi feito a partir de observações e posteriormente experiências para comprovar os fatos. Em alguns casos, as experiências eram feitas com o intuito de descobrir algo até então que não tinha sido observado. Os métodos tradicionais de ensino que abordam assuntos complexos fazem com que os estudantes não aprendam de forma significativa. Desta forma os estudantes acabam se tornando indiferentes ao conhecimento químico, ou seja, acham desinteressante (LEAL, 2009).

É necessária uma abordagem no ensino que vise ao campo macroscópico e microscópico, o que nem sempre acontece, logo, pode gerar um obstáculo epistemológico, ou seja, um entrave na aprendizagem, já que muitas vezes essas duas abordagens estão separadas perante o fazer pedagógico (LOPES, 1993). As barreiras que obstruem o entendimento dos estudantes podem ser denominadas de obstáculos epistemológicos (BACHELARD, 1996). Por exemplo, assuntos relativos às ligações químicas e à estrutura atômica necessitam de um maior grau de abstração, logo não se pode focar apenas no campo macroscópico (LÔBO, 2008; MOREIRA, 2011a).

A ciência contemporânea estuda teorias mistas, que induzem a formação de um simbolismo químico, como exemplificado por Gaston Bachelard. A correlação entre os aspectos conceituais químicos e empíricos dá-se o nome de "funcionamento da Química" que envolve os aspectos representacionais, teóricos e fenomenológicos, além das leis. Assim, "o funcionamento da Química é o modo como essa forma de conhecimento organiza suas explicações e seus esquemas representacionais em correlação com os fenômenos de interesse da Química e dos químicos" (LEAL, 2009, p. 14).

É importante que aspectos fenomenológicos, representacionais e teóricos sejam interligados, articulados no ensino, já que é inadequado trabalhar somente com a memorização de fórmulas, definições e equações químicas, pois não tem como observar de forma empírica as substâncias e conceitos abordados. Uma postura apenas centrada nas representações fará com os estudantes tenham dificuldades de compreender, interpretar os conhecimentos químicos (LEAL, 2009; LÔBO, 2008).

Geralmente há um certo formalismo ao abordar determinados conteúdos e isso torna o processo no âmbito escolar difícil já que a aplicabilidade dos mesmos no cotidiano é praticamente inexistente. Isso foge a ideia de representação de um conceito como apontam Astolfi e Develay (1995) e Lopes (1993), pois é necessário que os conceitos químicos interfiram num conceito já existente, logo sem aplicabilidade não tem como existir. $O$ estudo contemporâneo não tem mais 
relação com a memorização, mas sim, ao entendimento, compreensão, reflexão, produção do conhecimento científico.

Astolfi e Develay (1995) asseveram que há críticas as práticas do ensino tradicional no qual o professor apenas traz os seus saberes para que os alunos aprendam, não há uma construção coletiva do conhecimento. As respostas de determinados conceitos químicos são dadas de acordo com o conteúdo trabalhado, onde a capacidade de argumentação, reflexão e contextualização do estudante é desconsiderada. Os saberes adquiridos no dia a dia pouco têm importância nessa prática tradicional.

É imprescindível que os saberes prévios dos estudantes sejam considerados no âmbito escolar para que sejam sujeitos ativos. Ao se considerar os saberes prévios para a apreensão dos novos fará jus a teoria da aprendizagem significativa (TAS) de David Paul Ausubel. Essa destaca a importância do conhecimento prévio como fator isolado mais relevante na determinação do processo de ensino e aprendizagem em que ele a variável primordial para a teoria em que a nova interação, relação, modifica-o pela aquisição de novos significados (MOREIRA, 2011a). O referencial teórico que norteará a pesquisa será referente aos estudos realizados por Ausubel, baseado em Marcos Antônio Moreira.

Fugir do ensino tradicional é necessário para que se insira novas práticas em sala para diversificação, sair do uso monótono do livro e do quadro branco. De acordo com Miranda (2002) uma estratégia seria a utilização de jogos didáticos, que podem ajudar a atingir diversos objetivos, como os relacionados à cognição (desenvolvimento da inteligência e da personalidade), à simulação de vida em grupo, à motivação e a criatividade.

Os jogos educativos com finalidades pedagógicas revelam a sua importância pois promovem situações que proporcionam a um aumento da construção do conhecimento, introduzindo atividades que façam que o estudante seja participativo e se sinta importante no processo de ensino e aprendizagem, desenvolvendo a capacidade de iniciação e ação ativa e motivadora.

Os estudantes jogando podem se deparar com o desejo de ganhar e provoca uma sensação agradável em que situações problematizadoras condicionam a isso. Segundo Silveira e Barone (1998, p. 2): "[...] os jogos podem ser empregados em uma variedade de propósitos dentro do contexto de aprendizado. Um dos usos básicos e muito importantes é a possibilidade de construir-se a autoconfiança. Outro é o incremento da motivação". Até mesmo o mais simplório dos jogos pode ser empregado para proporcionar informações factuais e praticar habilidades, conferindo destreza e competência.

Os jogos podem ser utilizados como instrumentos de apoio, constituindo elementos úteis no reforço de conteúdos abordados em sala de aula. Em contrapartida, essa ferramenta de ensino deve ser instrutiva, transformada numa disputa prazerosa. De acordo com Fialho (2007) a exploração do aspecto lúdico pode se tornar uma técnica facilitadora para a elaboração de conceitos em prol da criatividade e o espírito de competição e cooperação, o que torna esse processo transparente.

Adicionalmente Miranda (2002) assevera que os jogos estimulam a curiosidade, a iniciativa e a autoconfiança assim como aprimoram o 
desenvolvimento de habilidades linguísticas, mentais e de concentração e exercitam o trabalho em equipe. Enquanto as atividades lúdicas, mais estritamente os jogos, podem assim auxiliar os estudantes na apropriação dos conteúdos, e consequentemente gerar um estímulo para estudar Química (MURCIA, 2005).

Diante do estudo realizado a pesquisa tem como propósito construir e elaborar um jogo como ferramenta pedagógica no ensino de Química para ser aplicado em uma escola estadual profissionalizante localizada em Fortaleza-Ce Brasil. Logo a presente investigação tem por objetivo analisar o uso de um jogo de tabuleiro no processo de ensino e aprendizagem de Química segundo o contexto da TAS. O jogo trata-se de um tabuleiro construído com de materiais de baixo custo. O nome dado ao jogo pelos estudantes foi "MixQuímico".

\section{TEORIA DA APRENDIZAGEM SIGNIFCATIVA}

A formação do sujeito enquanto professor ocorre a partir das suas experiências individuais e coletivas para que assim possa compreender o mundo e consequentemente atuar nele perante os saberes adquiridos. O conhecimento elaborado pelo estudante, pelo livro didático, pela fala do professor a partir das suas formas de abordar os assuntos e na tradição dos meios de comunicação devem ser considerados e reconhecidos (VIEIRA, 2012).

Lemke (2006) aponta como proposta para a aprendizagem a realização de estudos, investigações, quer de forma individual ou em grupos para o ensino, em que a aprendizagem em equipe, independente de idade, classe social, sexo ou cultura, irá acontecer de forma compartilhada, um ajudando o outro, de modo que seja instigada a reflexão acerca da atividade proposta. Para que haja a facilitação do conteúdo de Química que será abordado é necessário considerar o que o sujeito já sabe e isso implica na TAS.

A TAS é compreendida como um processo que envolve a reflexão, a compreensão e a concessão de significados do sujeito em interação com o meio social. Dessa forma a teoria se opõe a concepções inatistas de que o ser humano já nasce com características que são mantidas ao longo da sua trajetória de vida ou comportamentos que concebem as ações como forma de resposta aos estímulos externos. A TAS tem como origem de sua trajetória pessoal, profissional e suas experiências (MOREIRA, 2011a).

A aprendizagem significativa (AS) é aquela em que uma nova informação, que pode ser um conceito, ideia, símbolo significativo ou proposição, e que interage com aquilo que o aprendiz já sabe de uma maneira não-literal (substantiva) com uma ideia prévia já existente na sua estrutura cognitiva. A interação existente não será com qualquer saber prévio na estrutura cognitiva, mas sim com algum conceito, conhecimento nomeadamente relevante existente, logo, ocorrerá de maneira não arbitrária (AUSUBEL, 2003; MOREIRA, 2011a; NAVARRO, 2008).

Estrutura cognitiva é conceituada como um conjunto global de ideias sobre determinada disciplina, assunto ou mesmo um conjunto total de pensamentos do sujeito. Trata-se de a capacidade do sujeito reter informações, dados, conceitos, dentre outros atributos da aprendizagem. É nesta estrutura em que ocorre os processos de integração e organização dos novos conhecimentos (AUSUBEL, 
2003). O conhecimento já existente relevante à nova aprendizagem é denominado de subsunçor ou ideia-âncora.

Esse pode ser um símbolo, uma imagem, uma afirmação, construtos pessoais, até mesmo uma fórmula, algo que faça sentido perante o estudo que estiver sendo realizado. A interação proporciona que o novo conhecimento adquira significado para o sujeito, em que aqueles já existentes serão modificados, transformados. À proporção que o saber prévio serve de base para a nova informação ele se modifica. Logo a aquisição de novos conhecimentos não se dá pela quantidade de informações recebidas, mas sim, pela interação, pela relação que será ocasionada (AUSUBEL, 2003; MOREIRA, 2011a).

As novas informações vão interagir com os conceitos relevantes e inclusivos, reelaborando e se estabilizando de forma que venha a ser organizada e hierarquizada (VIEIRA, 2012). Os subsunçores são um suporte para o novo conhecimento que se deseja reter. A aprendizagem será mais significativa à medida em que o material incorporado ao aprendiz às suas estruturas de conhecimento adquirir sentido, significado, partir da relação com seu subsunçor. A ideia principal da teoria de Ausubel é a de que o aprendiz já sabe é o fator primordial para ser o ponto de partida a ser ensinado (MOREIRA, 1999).

O conhecimento prévio pode nem sempre ajudar nesse processo e pode funcionar como um obstáculo epistemológico, conforme Bachelard (1996), já que nem sempre é uma variável facilitadora. Um exemplo é considerar o átomo como um sistema planetário, o que dificulta o entendimento do estudante referente à estrutura do átomo quântico. Isso obstaculiza enormemente a AS do assunto (MOREIRA, 2009). É necessário verificar esse obstáculo e superá-lo a fim de que o saber científico seja predominante no ensino (BACHELARD, 1996)

Caso não haja conhecimentos prévios ou eles não sejam adequados a respeito de um determinado assunto, é sugerido como estratégia a elaboração de organizadores prévios que serão elaborados para servirem de ancoradouros para os conhecimentos a serem adquiridos, no caso, poderão suprir a deficiência de subsunçores (AUSUBEL, 2003). O organizador prévio pode ser um filme, uma situação-problema, uma leitura de capítulo ou qualquer outro meio, assim como aulas que precedem outras aulas.

O ideal é que, independente da forma que for utilizar esses meios, essas formas precedam a apresentação do material de aprendizagem e que sejam mais abrangentes e apresentem um nível de abstração maior. O organizador prévio tem como função primordial servir como ponte entre o saber que o aprendiz já conhece e aquele que deve ser introduzido a fim de que o novo conhecimento possa ser aprendido, compreendido (MOREIRA, 2011b).

Moreira (2011a) afirma do ponto de vista ausubeliano que existem duas condições para que possa ocorrer a AS que são: o material que será utilizado, seja livro, aplicativos, jogos, vídeos, dentre outros, deve ser potencialmente significativo e que seja relacionável de maneira não-literal e não-arbitrária a estrutura cognitiva do estudante; a outra condição é que o estudante precisa ter predisposição para aprender. Essa predisposição é quando ele está interessado em aprender os conteúdos que serão expostos pelo professor de forma que sua intenção não seja simplesmente em memorizar o assunto (AUSUBEL, 2003). 
Caso os conceitos estabelecidos pela TAS não sejam realizados, não aconteçam, haverá um tipo de aprendizagem denominada de mecânica (automática), na qual os novos conceitos a serem aprendidos não estarão relacionados a estrutura cognitiva do aprendiz (GUIMARÃES, 2009). Adicionalmente, Moreira (2011a, p. 130) explana que: "aprendizagem sem atribuição de significados pessoais, sem relação com o conhecimento preexistente, é mecânica, não significativa. Na aprendizagem mecânica, o novo conhecimento é armazenado de maneira arbitrária e literal na mente do indivíduo". Logo, foge ao conceito da TAS e o estudante é um receptor passivo na sala de aula.

A aprendizagem do tipo mecânica, puramente memorística, é aquela que mais é promovida e incentivada nas escolas, e nela o esquecimento do saber científico é rápido, já que os conteúdos ficam soltos ou ligados à estrutura mental de forma fraca. Entretanto a AS e a aprendizagem mecânica não se referem à uma dicotomia, na qual a última muitas vezes é necessária, como no caso de assuntos ou conceitos totalmente novos para o processo de aprendizado, contudo, posteriormente, ela poderá ser transformada em significativa na medida em que as novas informações adquiridas vão se transformando em subsunçores relevantes para a nova aprendizagem (MOREIRA, 2011b).

Há uma outra distinção de formas de processamento segundo a TAS entre aprendizagem por recepção (receptiva) e aprendizagem por descoberta (descobrimento). Esses tipos se referem à maneira como o sujeito receberá os conteúdos que deverá aprender. A primeira diz respeito a situação em que o aprendiz adquire o conhecimento a ser aprendido já na sua forma final, com todas as definições e significados, contudo, isso não significa que a aprendizagem esteja associada ao ensino tradicional. Já na segunda, há a descoberta, ou seja, é necessário que se descubra o que irá aprender. Do ponto de vista didático ela pode ser relevante e adequada a aprendizagens relacionadas a procedimentos científicos, por exemplo (MOREIRA, 2011a).

Mesmo sendo diferentes, é necessário que haja a incorporação da nova informação de forma não arbitrária e não-literal à estrutura cognitiva para que ocorra a AS (MOREIRA; MASINI, 1981). Esses tipos de aprendizagem também não se constituem em uma dicotomia, no caso, é ideal que ocorram de forma concomitante. Para que possa ser afirmado se houve aprendizagem por descoberta, por recepção ou na zona intermediária, ou seja, entre os dois processos, é necessário frisar a presença do pesquisador desde o começo do processo de intervenção (MOREIRA, 2011a).

Há dois processos que são os princípios programáticos facilitadores da AS que são denominados de diferenciação progressiva e reconciliação integradora ou integrativa. Eles caracterizam a estrutura cognitiva, que é constituída de uma estrutura dinâmica de subsunçores inter-relacionados e hierarquicamente organizados (MOREIRA, 2011a). A diferenciação progressiva é o processo no qual as ideias mais gerais, amplas, inclusivas da matéria de ensino devem ser apresentadas no início do ensino e, paulatinamente distinguidas em termos de detalhes e especificidades (MOREIRA; MASINI, 1981).

O conceito, proposição ou ideia deverá ser trabalhado desde o início, no caso, o aspecto mais importante. Em seguida deve ser trabalhada a partir de exemplos, atividades e/ou situações. É indispensável retomar o assunto através 
de sucessivas interações para que haja o favorecimento da sua progressiva diferenciação. Novos significados de forma contínua serão atribuídos a um dado subsunçor perante esse processo. Aprendendo de maneira significativa, ocorre essa diferenciação progressiva de significados dos novos saberes adquiridos no qual é percebida a diferença entre eles (MOREIRA; 2011b).

A reconciliação integradora (integrativa) acontece de forma simultânea a diferenciação progressiva, e consiste em integrar significados, esclarecer problemas, devendo ser exploradas relações entre conceitos e proposições, reconsiderar as diferenças e semelhanças dos conceitos num prisma mais global reconciliando as diferenças reais ou aparentes entre um determinado conceito, de modo a instigar a reestruturação cognitiva do estudante durante o processo (MOREIRA, 2011a).

\section{MATERIAIS E MÉTODOS}

A metodologia desta pesquisa teve uma abordagem qualitativa que perante Minayo (2002) é a via para o pensamento a ser utilizado e ocupa um lugar central na teoria. Trata-se basicamente do conjunto de técnicas a ser adotado para fundar a realidade. Isso ocorreu no espaço natural dos participantes, estudantes e professores, no decorrer de suas atividades letivas.

O importante na abordagem qualitativa é ser objetivo, permitindo aos instrumentos de trabalho uma mediação entre a teoria e a metodologia com a realidade empírica. Pesquisa que geralmente trabalha com pessoas, em que os sujeitos devem ser compreendidos dentro da realidade em que estão inseridos. A amostra de um grupo é válida nesse tipo de abordagem que é representativa, ou seja, condiciona ao estudo do fenômeno de maneira que possa atingir o objetivo almejado (MINAYO, 2002).

A reflexão do pesquisador é essencial para a coleta de dados assim como a variedade de abordagens e métodos utilizados. Os métodos qualitativos consideram ele como fator fundamental para a discussão dos dados. A subjetividade dele assim como dos sujeitos participantes torna-se parte do estudo (FLICK, 2009). A pesquisa qualitativa vai além de uma simples descoberta pois requer investigação, interpretação e compreensão e, para isso, um planejamento das atividades é imprescindível nesse processo. A coleta de dados segue um caminho num processo intuitivo (LUDKE; ANDRÉ, 1986).

De uma maneira geral há cinco características da pesquisa qualitativa: a fonte direta de dados é o ambiente natural, constituindo o pesquisador o instrumento principal; a pesquisa qualitativa é descritiva e explicativa; o pesquisador se interessa mais pelo processo do que simplesmente pelos resultados ou produtos; ele tende a analisar seus dados de forma indutiva; e o significado é de importância vital nessa abordagem (BOGDAN; BIKLEN, 1994).

No campo da abordagem qualitativa, realizou-se um estudo de caso como método da pesquisa que Yin (2005, p. 32) trata como "uma investigação empírica que investiga um fenômeno contemporâneo dentro de seu contexto da vida real, especialmente quando os limites entre o fenômeno e o contexto não estão claramente definidos". Um estudo de caso deve proporcionar uma imagem a mais fiel e digna possível da realidade pesquisada em suas várias dimensões, dentro de sua real complexidade (SÁ; QUEIROZ, 2010). Pode ser caracterizado 
como um estudo de uma entidade bem demarcada, como um programa, uma escola ou uma unidade social. Gil (2002) aponta que esse estudo não aceita um roteiro rígido para a sua delimitação, porém é necessário seguir um caminho, uma estratégia para atingir o objetivo proposto.

Para análise dos dados os sujeitos da investigação receberam a sua identificação através dos números de 1 a 28 com a finalidade de preservar seu anonimato. Reforçado pela "a resolução CNS 196/96 adota no seu âmbito a prevenção de procedimentos que asseguram a confidencialidade e a privacidade[...]" (BRASIL, 2012).

Tendo em vista que se trata de uma pesquisa envolvendo seres humanos, procurou-se atender exigências do Comitê de Ética em Pesquisa (CEM), conforme a Resolução 466/12 do Conselho Nacional de Saúde (CNS). Logo, foi enviado aos pais dos estudantes participantes um Termo de Consentimento Livre e Esclarecido, solicitando a autorização dos mesmos e esclarecendo aspectos relativos à concretização da pesquisa.

No caso, foi colocado como sugestão a criação do jogo e os estudantes concordaram com a ideia. Aplicou-se para 28 estudantes do Curso Profissionalizante ou Técnico de Nutrição e Dietética. Eles disponibilizaram-se em participar da pesquisa e todos são da $1^{\circ}$ série do Ensino Médio de uma escola estadual profissionalizante em Fortaleza-Ce. Essa turma foi escolhida pelo fato de apresentar o menor rendimento na disciplina de Química conforme levantamento realizado no primeiro e segundo bimestre do ano de 2017. Os assuntos abordados de Química foram substâncias e misturas, processos de separação de misturas, tabela periódica e ligações químicas interatômicas. Os assuntos escolhidos foram sugestões da professora da referida escola pois já haviam sido abordados em sala de aula, logo ajudaria no processo de apreensão do saber.

Para coleta de dados escolheu-se de forma aleatória o tema substâncias e misturas para ter elementos fornecedores da pesquisa. Qualquer outro tema poderia ter disso escolhido já que todas as atividades propostas foram abordadas tanto em sala de aula como através do jogo. A pergunta escolhida mostrada na Figura 1 foi a que os estudantes apresentaram maior dificuldade na resolução e cogitavam conforme evidenciado a aplicação da mesma de forma prática. Vale ressaltar que todas as outras perguntas corroboraram para a aprendizagem dos conteúdos. A resolução da questão foi realizada em sala de maneira individual. 
Figura 1 - Pergunta norteadora da pesquisa.

Questão 5) Para que você seja contratado na empresa "Umbrella Corporation 123 " deverá demonstrar os seus conhecimentos na área da Química. A empresa realiza diversos tipos de misturas, dentre as quais homogêneas e heterogêneas. Mistura é uma porção de matéria que corresponde à adição de duas ou mais substâncias puras. Veja a colocação de um estudante abaixo:

"Eu realizei uma mistura bem interessante na aula de Química. Eu utilizei corante, água, feijão, álcool e óleo, respectivamente. Algumas substâncias se misturaram com as outras".

Marque a alternativa que especifica corretamente o número de componentes e de fases da mistura realizada.

a) 4 componentes e 5 fases.

b) 4 componentes e 4 fases.

c) 5 componentes e 4 fases.

d) 5 componentes e 5 fases.

e) 5 componentes e 3 fases.

(Fonte: Autores, 2017.)

A resposta correta da questão não foi informada em sala pois os estudantes iriam respondê-la novamente no momento da aplicação do jogo em forma de desafio que consistia na associação da teoria com a prática. Dessa forma será verificado se a atividade contribuiu na apreensão do saber. No decorrer da atividade o professor assume a função de mediador, incentivando também a cooperação e discussões (MIRANDA, 2002). Essa ferramenta também serve para trabalhar o domínio cognitivo dos estudantes em razão do estímulo para a elaboração de perguntas e desafios.

Outro instrumento utilizado foi a aplicação de um questionário em que é uma excelente técnica para recolher os dados em que consiste na elaboração de um formulário normalizado, estruturado a fim de facilitar a discussão das análises realizadas no decorrer da pesquisa (MEIRINHOS; OSÓRIO, 2010). O questionário foi aplicado no final da pesquisa com todos os sujeitos participantes cujo intuito foi discutir os aspectos que podem ser melhorados, aperfeiçoados através deste recurso.

A predominância da pesquisa é qualitativa, porém há análises de dados perante os questionários que serão aplicados a fim de contribuir na discussão apresentada. O pesquisador qualitativo, segundo Moreira (2011b), transforma dados e casualmente faz uso de tabelas, quadros e/ou sumários, porém, o que prevalece é uma análise descritiva em que não há preocupação com inferências estatísticas.

Em suma a pesquisa foi dividida em quatro etapas: na primeira etapa aconteceram aulas sobre os assuntos para sondar os saberes prévios a partir de debates e questões. Foram 08 aulas teóricas com carga horária total de 16 horas e nesse período discutiu-se a forma de confecção do jogo com 05 estudantes que se disponibilizaram a ajudar; na segunda etapa, houve a construção do jogo de tabuleiro assim como a elaboração das perguntas e desafios pelos estudantes; na terceira etapa, realizou-se a aplicação do jogo; na quarta etapa aplicou-se um questionário subjetivo para verificar os aspectos positivos e negativos da atividade. Em todas as etapas a presença do pesquisador foi importante. 


\section{PROCESSO DE CONSTRUÇÃO E APLICAÇÃO DO JOGO MixQuímico}

Para a confecção do jogo MixQuímico foram utilizados os seguintes materiais: pedaço de madeira no formato de um quadrado, cartolina, cola, tesoura, papelão, canetinhas, lápis de cor, massas de modelar, palitos de fósforo e papéis ofício. Outros materiais foram utilizados para a realização dos desafios, como arroz, feijão, água, álcool, açúcar, sal, vinagre, botões, dentre outros.

As cores existentes no tabuleiro são correspondentes aos conteúdos que são: vermelho, verde, laranja e rosa. Cada cor apresenta questões relacionadas a um conteúdo específico. Pode jogar no mínimo dois jogadores onde os mesmos podem eleger o conteúdo que mais se identificam e tenham maior habilidade. É interessante que o professor esteja presente para coordenar, anotar os pontos do jogo e constatar se acertaram as questões. Caso haja o interesse pelo mesmo conteúdo recomenda-se um sorteio para decidir.

Em relação ao formato o tabuleiro foi construído através de um pedaço madeira oriundo de um guarda-roupa que não era mais utilizado. Esse pedaço foi dividido em quatro partes na forma de um quadrado em que cada parte contém 45 "casas". Cada espaço seria referente à um conteúdo. O pesquisador foi responsável de coordenar o jogo em que anotava os pontos dos participantes adquiridos durante a partida. Ganha o jogo aquele que obter maior pontuação e chegar no final. Abaixo segue a Figura 2 referentes ao jogo construído:

Figura 2 - Jogo em formato de tabuleiro elaborado pelos estudantes.

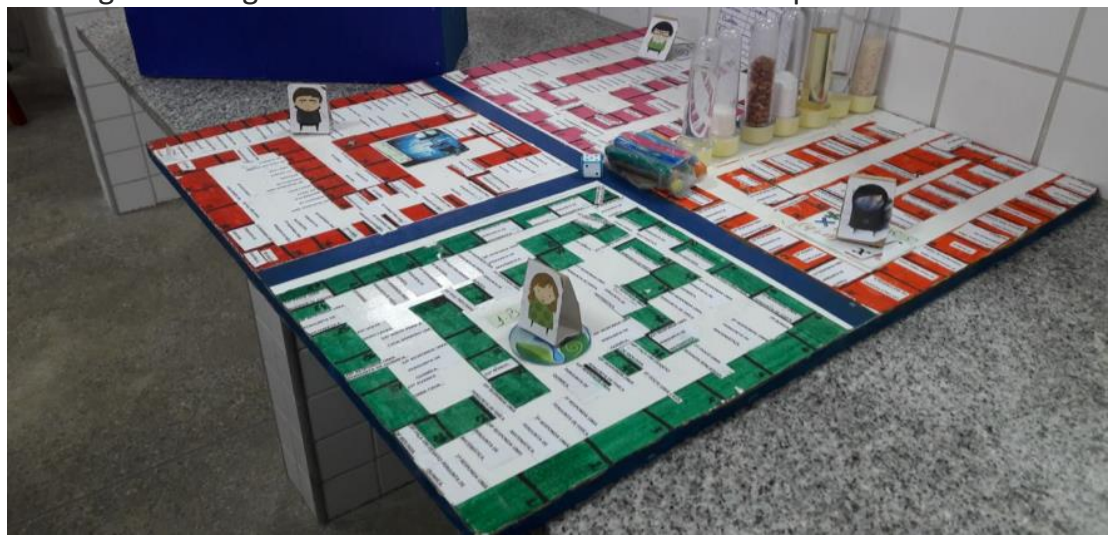

(Fonte: Autores, 2017.)

Para que ficasse ainda mais organizado foi construído uma caixa de madeira para serem colocadas as perguntas e os desafios referentes ao jogo (ver Figura 3): 
Figura 3 - Caixa contendo as perguntas e os desafios.

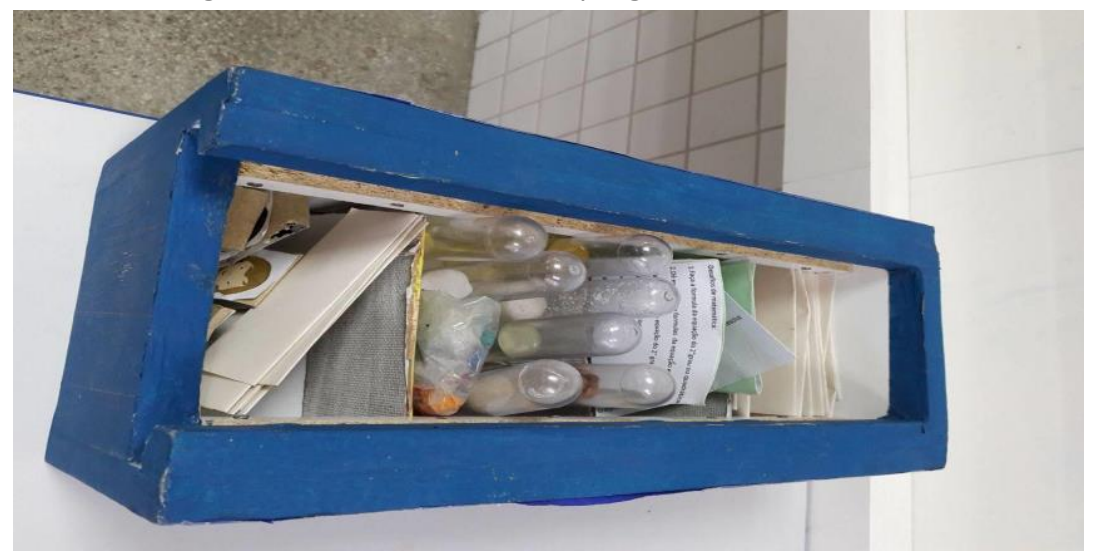

(Fonte: Autores, 2017.)

Podem jogar no mínimo dois jogadores e no máximo quatro. No tabuleiro possui perguntas, desafios, bônus e pegadinhas (volte uma casa, fique uma rodada sem jogar, dentre outras). Algumas casas no tabuleiro equivaleriam a bônus em que correspondiam a pontos extras que variavam entre um a cinco. Das 45 "casas" tinham 18 perguntas objetivas e subjetivas, 15 desafios, 07 bônus e 05 pegadinhas. Cada jogador ao longo da partida possui o direito a três bônus conforme apresentado abaixo (Figura 4).

Figura 4 - Bônus que podem ser usados ao longo do jogo.

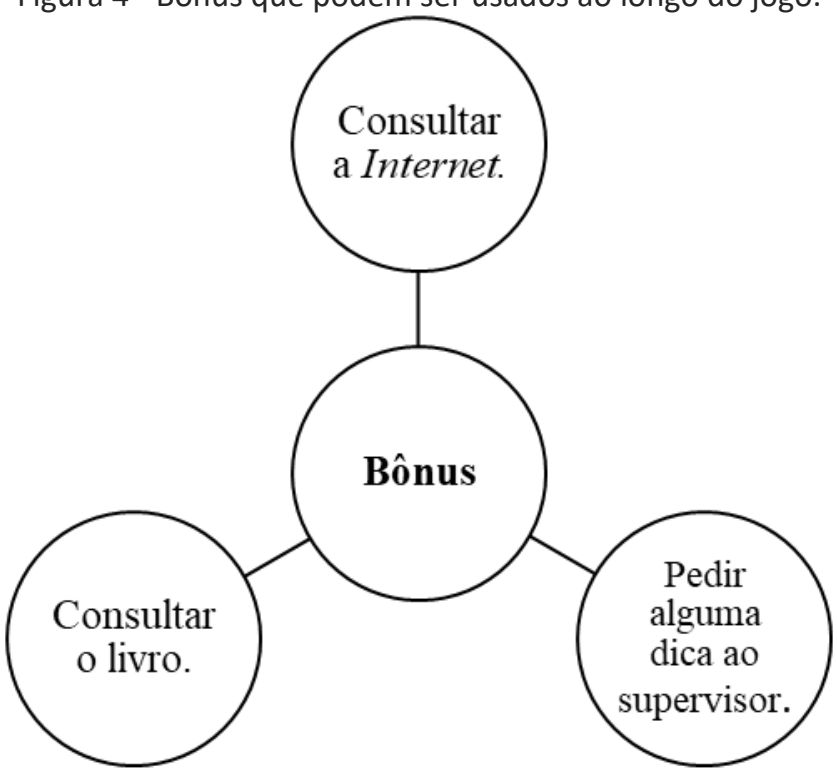

(Fonte: Autores, 2017.)

Os estudantes tinham o direito de acessar a internet pelo menos duas vezes para a realização de uma pesquisa sobre o tema abordado caso não soubesse a resolução. Isso mostra que o uso dessa ferramenta também pode estar associado aos jogos fazendo o estudante perceber que existem outros meios de pesquisa. Segundo Valente (1996) o uso do computador também vem ganhando potência e se tornando cada vez mais portátil atraindo o público. A internet passou a ser fundamental como entretenimento, estudos, trabalhos e pesquisas. É importante que verifique a fonte das respostas pois nem sempre apresentam informações que estejam de acordo com o saber científico. 
Os estudantes acabam sendo companheiros no jogo, o tornando mais interessante, dinâmico. Cada resposta correta dos desafios equivale a sete pontos, já as perguntas equivalem a quatro. Caso o participante errasse o desafio não perderia ponto, apenas retornaria duas casas. Os desafios consistem em situações problematizadoras em que deveriam realizar pequenos experimentos ou montar as moléculas solicitadas de acordo com o problema.

$\mathrm{Na}$ aplicação do jogo os estudantes foram divididos em quartetos em que cada um deveria escolher o tema que tinha mais facilidade, sendo que, em momentos em que haviam a escolha do mesmo tema era realizado um sorteio para decidir. Foram realizados no total 15 partidas para que todos fossem contemplados. Cada partida levava, em média, de 25 a 40 minutos. O pesquisador estava sempre presente para coordenar e anotar os pontos da partida.

\section{RESULTADOS E DISCUSSÃO}

Após as aulas teóricas foram aplicadas as questões sobre os assuntos e para análise dos dados uma questão de forma aleatória foi escolhida conforme mencionado. Sobre a resolução da mesma constatou-se que apenas $29 \%$ escolheram a alternativa correta. Porém, 64\% escolheram o item " $\mathrm{C}$ " e 7\% escolheram a alternativa " $A$ ". Abaixo segue o Gráfico 1 referentes a esses resultados:

Gráfico 1 - Escolha do item pelos estudantes.

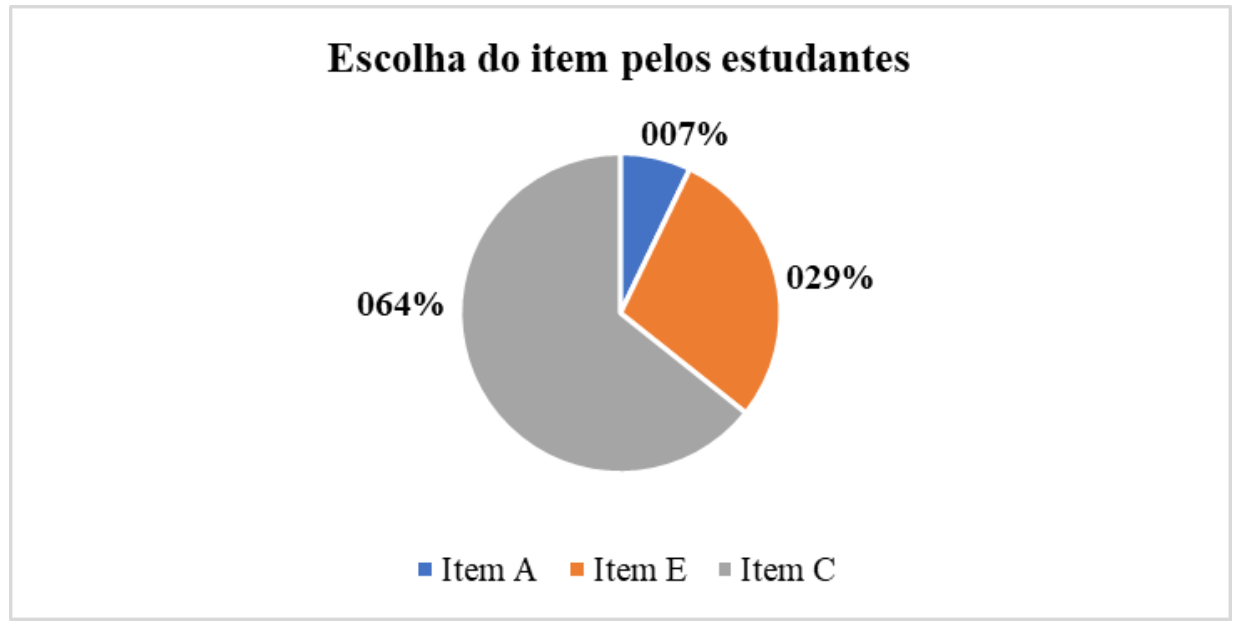

(Fonte: Autores, 2017.)

Perante o resultado obtido somente a aula teórica não foi suficiente pois a maioria optou pelo item errado, diante disso é importante que haja outros recursos metodológicos em sala de aula para que a compreensão do conceito químico possa ser de maneira ampla. Percebeu-se que a maioria dos estudantes não sabiam se uma determinada substância quando misturada com outra ficaria com aspecto homogêneo ou heterogêneo, logo o estudo da Química deve estar ligado a experimentação em que a teoria e a prática são indissociáveis no qual é uma forma de facilitar a compreensão estudantes possam ser reflexivos e serem mais ativos no processo de 
aprendizagem. A experimentação é importante dentro do ensino de Química em que associa a teoria com a prática (HODSON, 1988). O uso de exercícios de cunho reflexivo e práticas contribuem para a AS (MOREIRA, 2011b).

Dentro do processo de ensino e aprendizagem os saberes prévios também devem ser levados em consideração em que a reflexão durante as aulas é essencial para que as ideias possam ser explícitas e que se inter-relacionem com os novos conceitos científicos (AUSUBEL, 2003). Cabe aos estudantes com o intermédio do professor reestruturar as ideias em sua estrutura cognitiva para se chegar a sua conclusão. Nesse sentido, a experimentação pode ajudar esse processo (SARAIVA et al., 2017).

A experimentação contribui para o refinamento dos conceitos assim como auxilia na quantificação conceitual. Condiciona também a um estabelecimento dos limites da aplicabilidade da teoria (HODSON, 1988). Segundo o trabalho realizado por Saraiva et al. (2017) o uso da experimentação no ensino de Química pode proporcionar que o estudante seja ativo dentro do processo de ensino e aprendizagem desde que haja um condicionamento para isso, por conseguinte é necessário que os mesmos sejam desafiados e motivados para a resolução de problemas e exista problematização.

Os experimentos são um excelente meio para a consecução do saber científico, entretanto muitos aspectos da ciência não são intrinsicamente relacionados à experimentação já que muito do progresso teórico da ciência foi desenvolvida e reforçada também por outras formas de análise, como por exemplo a geologia em que determinados estudos não requerem o uso de nenhum experimento. Há experimentos que são indesejáveis por razões éticas, portanto o conhecimento teórico não se restringe a experimentos (HODSON, 1988).

A experimentação não pode ser considerada como uma atividade que conseguirá alcançar todos os objetivos da aula proposta. Os professores ao executarem tais atividades não devem ter a visão de apenas comprovar a teoria vista em sala de aula no laboratório tendo em vista revisar os conceitos já abordados em sala de aula. Muitos também só focam em uma mera coleta de dados desvinculados a vida dos estudantes (SARAIVA, 2017).

Após a abordagem teórica em sala de aula aconteceram encontros para a aplicação do jogo MixQuímico. Na Figura 5 apresenta-se a realização de um desafio. Ele é referente a questão proposta na pesquisa, porém deveriam realizar a mistura na prática utilizando os materiais existentes na caixa. 
Figura 5 - Realização de um desafio pelos estudantes.

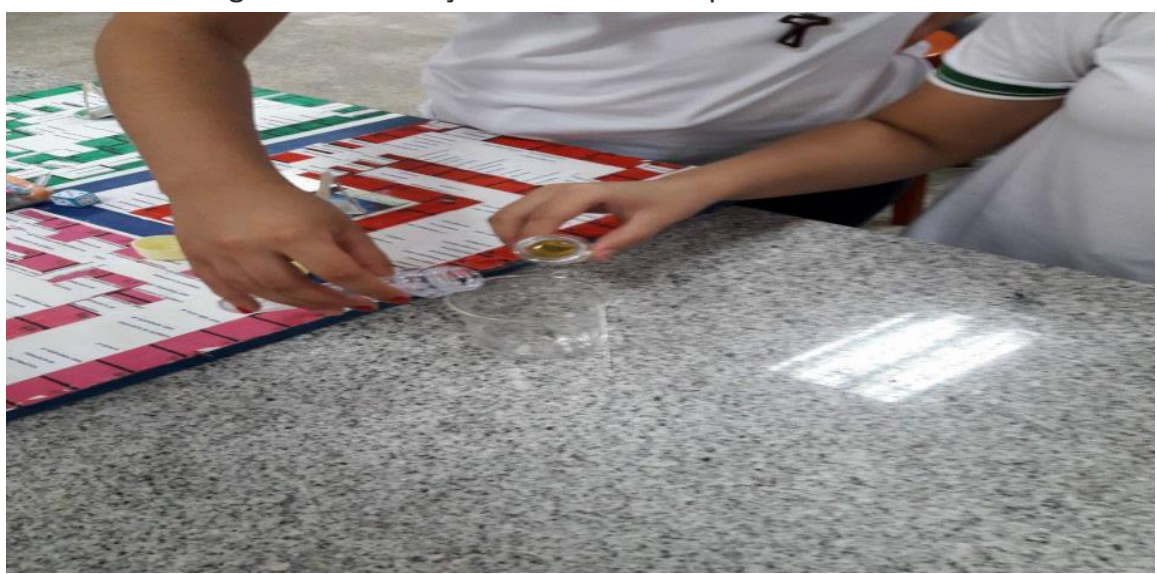

(Fonte: Autores, 2017.)

Após a realização do jogo, verificou-se que todos os participantes acertaram a questão, marcando o item " $E$ " que são 5 componentes e 3 fases. Os estudantes durante o jogo foram se ajudando na resolução tanto nas questões quanto nas práticas. Eles, em grupo, cogitam uma hipótese e a partir dela buscam estratégias para confirmar ou não a proposta solicitada. Trata-se de uma atividade cooperativa que se encontra segundo o contexto da TAS (AUSUBEL, 2003). Essa ação permitiu verificar possíveis indícios de uma AS através do seu uso perante os desafios que foram realizados.

AS acontece quando as práticas pedagógicas favorecem a mudança conceitual da estrutura cognitiva do estudante por meio da interação entre os seus saberes prévios e as novas informações. O jogo MixQuímico propiciou o equilíbrio entre os conceitos novos e os já existentes, ao permitir ao estudante o agir com o mundo e retirar desta relação novas informações, as quais possibilitam a interpretação deste, gerando novas experiências.

O jogo mostrou-se como material potencialmente significativo ao facilitar o processo de apreensão onde através do desafio escolhido houve uma melhor compreensão do assunto. Esse fato diz respeito à uma das condições da TAS. Os estudantes construíram mais adequadamente os conceitos relacionados aos conteúdos abordados, em que os novos conhecimentos foram se modificando, ganhando significados (MOREIRA, 1999). Essa inter-relação do conteúdo apresentado pelo professor com um conceito relevante existente na estrutura cognitiva do estudante é capaz de facilitar o aprendizado de novos conceitos na sua estrutura cognitiva.

Conforme a aplicação de um questionário em que deveriam explanar os aspectos positivos e negativos do jogo, verificou-se que $100 \%$ afirmaram que tiveram um aprendizado mais significativo e diferenciado devido ao jogo já que proporciona uma atividade prazerosa em que instiga a criatividade, interação e dinamização. Não foram citados aspectos negativos, mas sugeriram que o mesmo deveria ser aplicado todo semestre letivo. O uso dessa ferramenta foge ao modelo tradicional de ensino logo concorre para que tenha esse resultado conforme discutido. $\mathrm{O}$ jogo sendo aplicado no intuito de ensinar, praticar e compartilhar ideias define o aspecto relevante de sua utilização (MURCIA, 2005).

Merece destaque a resposta do sujeito 12: "achei bem interessante pois as questões aplicadas em sala foram as mesmas do desafio e isso me ajudou 
bastante pois eu já tinha alguns conhecimentos a respeito". O processo de interação entre os subsunçores e os novos saberes é interativo e dinâmico, logo o novo saber vai adquirindo novos significados, corroborando com os já existentes e o conhecimento vai sendo construído. Os subsunçores vão ficando mais estáveis, diferenciados, ou seja, ricos em significado o que pode facilitar novas aprendizagens. $O$ processo de ensino e aprendizagem deve fazer sentido para o estudante para que haja essa interação (MOREIRA, 2011a).

Entretanto, o professor deve estar atento com a mobilização da ânsia do estudante em relacionar o novo material à sua estrutura cognitiva com o intuito de não correr o risco de ter uma aprendizagem mecânica (AUSUBEL, 2003). Caso o desejo e a disposição do estudante estejam em evidência e o material que vem a ser planejado pelo professor seja potencialmente significativo, que são as condições para haver AS conforme mencionadas, haverá a AS, do contrário, será obtida apenas uma aprendizagem mecânica (MOREIRA, 2011a). Tanto a disposição em aprender ficou evidente como o jogo foi potencialmente significativo perante a pesquisa.

Para que o estudante possa ter uma AS a investigação deve fundamentar-se na sua própria ação. É ele que deve agir na tentativa de interligar esses novos conceitos propostos em sua estrutura cognitiva perante aquilo que já sabe (AUSUBEL, 2003), contudo este processo não ocorre de forma deliberada e é de suma importância que o professor intervenha no ensino, ocasione a reflexão, os conhecimentos prévios, a argumentação e a discussão, pois são estes fatores que movimentam o estudante a ancorar os novos conceitos. Isso aconteceu através do uso jogo em que foi construído pelos próprios estudantes.

É necessário utilizar situações que sejam novas para intensificar o processo de ensino e aprendizagem. Os usos dos desafios corroboram para isso conforme evidenciado. $O$ processo de compreensão e, aprendizagem, depende do que ele já sabe (NAVARRO, 2008). O desenvolvimento de novas metas é imprescindível onde devem contribuir dentro do processo de ensino e aprendizagem (LEMKE, 2006). O sujeito 28 afirmou: "peguei um desafio que tinha que montar a molécula da água com massinha, tinha material e tudo e eu consegui, o jogo só tem coisa boa, nada negativo". Os desafios eram os que mais chamavam atenção no desenvolvimento da atividade.

Atividades como jogos podem ser usados para apresentar obstáculos e desafios a serem vencidos, como forma de fazer com que os estudantes atuem em sua realidade o que envolve, portanto, o interesse e o despertar deste. Com o interesse do estudante a aprendizagem será uma decorrência natural (MURCIA, 2005). De acordo com Miranda (2002) esse tipo de atividade promove um estímulo e interesse para a participação em sala de aula, condicionando ânimo e entusiasmo. Fato este observado durante a execução do jogo e a vontade dos estudantes de participar novamente em outras partidas.

Segundo o sujeito 21: "foi bastante divertido o jogo, eu ficava com medo de errar, mas eu queria responder e os desafios me deixavam bem animada, sempre ficava curiosa, quero jogar de novo". O uso do jogo explicitou que há um entusiasmo e curiosidade, motivando uma aprendizagem efetiva do conteúdo abordado, proporcionando uma aula mais dinâmica e divertida. De acordo com Murcia (2005) o jogo apresenta um caráter voluntário perante a motivação existente para participar da atividade, no caso, uma motivação interna que 
acontece de forma prazerosa muitas vezes oriunda de desafios presentes no jogo.

Quando o estudante se lembra do jogo o conceito aparece naturalmente e quando se é discutido, logo, se relaciona o conceito em sala. O professor na tarefa de construção e de reestruturação de conceitos proporciona a ativação dos conhecimentos prévios dos estudantes e articula esses conhecimentos a uma nova informação que está sendo apresentada. A relação do jogo com os conteúdos como uma nova abordagem de ensino poderá ser uma opção ou um caminho para o melhor desempenho escolar no ensino de Química (FIALHO, 2007).

A reflexão é imprescindível para saber os conceitos que devem ser mantidos e alterados. Para isso a ação da escolha das maneiras de agir em prol da aprendizagem estar interligada a autoconsciência e na adesão ao aderir ser professor, já que implica a aderir a princípios, valores, adotar posturas que visam no crescimento profissional e pessoal do docente ou do futuro docente seja qual for a área de ensino (PIMENTA; ANASTASIOU, 2014).

Segundo Lemke (2006) é necessário oferecer uma educação científica que faça com que os estudantes possam ter outras formas de ver o mundo tendo em vista a habilidade de desenvolver seu pensamento crítico, de ser reflexivo perante o cenário atual vigente. O desenvolvimento de novas metas é imprescindível onde devem contribuir dentro do processo de ensino e aprendizagem e, consequentemente, para a sociedade e a vida das pessoas. É importante que a aprendizagem adquirida seja para toda a vida, que dure o máximo possível, que condicione a debates, análises, críticas e reflexões.

\section{CONSIDERAÇÕES FINAIS}

No âmbito escolar o jogo ajudou na elaboração de aulas diferentes e dinâmicas no qual houve uma interação maior do professor com a turma e dos estudantes entre si, o que pode aumentar o desenvolvimento e desempenho da turma, além de maior concentração no conteúdo dado. Vele ressaltar que várias disciplinas podem ser trabalhadas através deste recurso. O jogo MixQuímico tem finalidade de aprimorar os conhecimentos e a criatividade através da estimulação do pensamento lógico e estratégico, motivando o desejo de pesquisar, fazendo com que adquira mais conhecimento através da leitura, fato este comprovado na execução.

A relação do jogo com os conteúdos de Química como uma nova abordagem de ensino poderá ser uma opção ou um caminho para o melhor desempenho escolar e o apreço pela ciência. Portanto, a atividade aplicada foi relevante no qual o conteúdo pode ser revisado de uma maneira diferente. $O$ jogo de tabuleiro elaborado corroborou aos estudantes uma chance a mais de assimilar o conteúdo que foi estudado e contribuiu para identificar indícios de uma AS. Percebeu-se que os estudantes interagiram muito bem e reforçaram o conteúdo visto em sala. Com base ainda nos resultados obtido concluiu-se na eficácia do jogo enquanto material didático de apoio para a escola.

O jogo construído e aplicado oferece estímulo e dinamicidade no processo de ensino e aprendizagem onde propicia o desenvolvimento espontâneo e criativo dos estudos além de viabilizar que o professor amplie seus 
conhecimentos sobre técnicas ativas de ensino, se aperfeiçoe profissionalmente, estimulando-o a recriar sua prática pedagógica. O professor pode adaptá-lo conforme suas necessidades, seja nas regras ou na condução do mesmo. Permite uma possibilidade a mais na construção do conhecimento, na compreensão. A experimentação também mostrou ser uma estratégia promissora visto que facilita a compreensão do novo saber em que instiga o estudante a ser participativo. 


\title{
Analysis of the game MixQuímico in the teaching of chemistry according to the context of theory of meaningful learning
}

\begin{abstract}
The objective of this research is to analyze the use of a pedagogical board game in the teaching and learning process of Chemistry under the context of Significant Learning Theory. The game consists of a board built with materials of low cost with four divisions that approach different contents of Chemistry. The subjects of the research were high school students of a state vocational school in Fortaleza. A qualitative approach based on the case study was used as methodological field. According to the results the students presented evolution of their acquired concepts in which they were being improved in the acquisition of new meanings through the use of the game MixQuímico. This corroborated one more chance to assimilate the content that was studied and contributed to identify indications of Meaningful Learning. On the basis of the results obtained, the effectiveness of the game was concluded as supporting teaching material.
\end{abstract}

KEYWORDS: Chemistry teaching. Board game. Meaningful learning. 


\section{REFERÊNCIAS}

ASTOLFI, J-P.; DEVELAY, M. A Didática das Ciências. Campinas: Papirus, 1995.

AUSUBEL, D. P. Aquisição e retenção de conhecimentos: uma perspectiva cognitiva. Lisboa: Plátano Edições Técnicas, 2003.

BACHELARD, G. A formação do espírito científico: contribuição para uma psicanálise do conhecimento. Editora Contraponto, 1996.

BOGDAN, R. C.; BIKLEN, S. K. Investigação qualitativa em educação: uma introdução à teoria e aos métodos. Portugal: Porto Editora, 1994.

BRASIL. Lei no 9.394, de 20 de dezembro de 1996. Estabelece as Diretrizes e Bases da Educação Nacional. Diário oficial da República Federativa do Brasil, Brasília, DF, 1999.

Resolução de $n^{\circ} 466,12$ de dezembro de 2012. Conselho Nacional de Saúde. Disponível em:

<http://bvsms.saude.gov.br/bvs/saudelegis/cns/2013/res046612 12 2012.html >. Acesso em: 09 jan. 2017.

Resolução № 196/96. (2012). Comissão Nacional de Ética Em Pesquisa, Brasília: Ministério da Saúde.

FIALHO, N. N. Jogos no Ensino de Química e Biologia. Curitiba: IBPEX, 2007.

FLICK, U. Introdução à pesquisa qualitativa. Porto Alegre: Artmed, 2009.

GIL, A. C. Como elaborar projetos de pesquisa. São Paulo: Atlas, 2002.

GUIMARÃES, C. C. Experimentação no ensino de química: Caminhos e Descaminhos rumo à aprendizagem significativa. Química Nova na Escola, v. 31 (3), p. 198-202, 2009.

HODSON, D. Experimentos na Ciência e no ensino de Ciências. Educational Philosophy and Theory. Tradução de Paulo A. Porto, v. 20, p. 53-66, 1988. 
LEAL, M. C. Didática da Química: Fundamentos e práticas para o ensino médio. Belo Horizonte: Dimensão, 2009.

LEMKE, J. L. Investigar para el futuro de la educación científica: nuevas formas de aprender, nuevas formas de vivir. Enseñanza de las ciencias, v. 24 (1), p. 5-12, 2006.

LÔBO, S. F. O ensino de Química e a formação do educador químico, sob o olhar bachelardiano. Ciência \& Educação, Bauru, v. 14 (1), p. 89-100, 2008.

LOPES, A. R. C. Contribuições de Gaston Bachelard ao Ensino de Ciências.

Enseñanza d de las Ciencias, Barcelona, v.11 (3), p. 324-330, 1993.

LUDKE, M; ANDRÉ, M. E. D. A. Pesquisa em educação: abordagens qualitativas. São Paulo: EPU, 1986.

MEIRINHOS, M; OSÓRIO, A. O estudo de caso como estratégia de investigação em educação. EduSer: revista de educação. v. 2(2), p. 49-65, 2010.

MINAYO, M.C. S. Pesquisa Social: Teoria, Método e Criatividade. Petrópolis, Rio de Janeiro: Vozes, 2002.

MIRANDA, S. No Fascínio do jogo, a alegria de aprender. In: Ciência Hoje, v. 28 (8), Brasília, p. 21-34, 2002.

MOREIRA, M. A. Aprendizagem Significativa: a teoria e textos complementares. São Paulo: Livraria da Física, 2011a.

MOREIRA, M.A.; MASINI, E. F. S. Aprendizagem Significativa - a teoria de David Ausubel. São Paulo: Moraes Ltda, 1981.

M. A. Metodologias de Pesquisa em Ensino. São Paulo: Livraria da Física, 2011b.

M. A. Subsídios teóricos para o professor pesquisador em ensino de ciências: A teoria da aprendizagem significativa. Porto Alegre: não informado, 2009.

MURCIA, J. A. M. Aprendizagem Através do Jogo. Porto Alegre: Artmed, 2005. 
NAVARRO, M. R. Procesos Cognitivos y Aprendizaje Significativo. Madrid. Comunidad Autónoma. Servicio de Documentación y Publicaciones, 2008.

PIMENTA, S. G.; ANASTASIOU, L. G. C. Docência no Ensino Superior. São Paulo: Cortez, 2014.

SÁ, L. P.; QUEIROZ, S. L. Estudo de casos no ensino de química. Campinas, SP: Editora Átomo, 2010.

SARAIVA, F. A; VASCONCELOS, A. K. P.; LIMA, J. A.; SAMPAIO, C. G. Atividade Experimental como Proposta de Formação de Aprendizagem significativa no Tópico de Estudo de Soluções no Ensino Médio. Thema. Fortaleza (Ceará). v. 14, n. 2, p. 194 - 208, nov. 2017.

SARAIVA, F. A. Concentração de soluções no Ensino Médio: o uso de atividades experimentais para uma aprendizagem significativa. Instituto Federal de Educação, Ciência e Tecnologia do Ceará - IFCE. 2017. Dissertação (Mestrado). IFCE - Fortaleza - CE, 2017.

SILVEIRA, R. S.; BARONE, D. A. C. Jogos Educativos computadorizados utilizando a abordagem de algoritmos genéticos. Universidade Federal do Rio Grande do Sul. Instituto de Informática. Curso de Pós-Graduação em Ciências da Computação, 1998.

VALENTE, J. A. O Professor no Ambiente Logo: formação e atuação. São Paulo: Impresso Gráfica - UNICAMP, 1996.

VIEIRA, F. A. C. Ensino por Investigação e Aprendizagem Significativa Crítica: análise fenomenológica do potencial de uma proposta de ensino. Universidade Estadual Paulista. 2012. Tese (Doutorado). Faculdade de Ciências, Universidade Estadual Paulista, Bauru- SP, 2012.

YIN, R. K. Estudo de caso: planejamento e métodos. Porto Alegre: Bookman, 2005. 
Recebido: 2018-04-16

Aprovado: 2018-11-05

DOI: $10.3895 /$ rbect.v12n2.8153

Como citar: SILVEIRA, F. A.; VASCONCELOS, A. K. P.; SAMPAIO, C. G. Análise do jogo MixQuímico no ensino de química segundo o contexto da teoria da aprendizagem significativa. Revista Brasileira de Ensino de Ciência e Tecnologia, v. 12, n. 2, 2019. Disponível em: <https://periodicos.utfpr.edu.br/rbect/article/view/8153>. Acesso em: xxx.

Correspondência: Felipe Alves Silveira - felipesilveiraquimica@gmail.com Direito autoral: Este artigo está licenciado sob os termos da Licença Creative Commons-Atribuição 4.0 Internacional. 